\title{
Degradation of 4-fluorophenol by Arthrobacter sp. strain IF1
}

\author{
Maria Isabel M. Ferreira • Julian R. Marchesi • \\ Dick B. Janssen
}

Received: 23 October 2007 / Revised: 26 December 2007 / Accepted: 30 December 2007 / Published online: 29 January 2008

(C) The Author(s) 2008

\begin{abstract}
A Gram-positive bacterial strain capable of aerobic biodegradation of 4-fluorophenol (4-FP) as the sole source of carbon and energy was isolated by selective enrichment from soil samples collected near an industrial site. The organism, designated strain IF1, was identified as a member of the genus Arthrobacter on the basis of $16 \mathrm{~S}$ ribosomal RNA gene sequence analysis. Arthrobacter strain IF1 was able to mineralize 4-FP up to concentrations of $5 \mathrm{mM}$ in batch culture. Stoichiometric release of fluoride ions was observed, suggesting that there is no formation of halogenated dead-end products during 4-FP metabolism. The degradative pathway of 4-FP was investigated using enzyme assays and identification of intermediates by gas chromatography (GC), GC-mass spectrometry (MS), highperformance liquid chromatography, and liquid chromatography-MS. Cell-free extracts of 4-FP-grown cells contained no activity for catechol 1,2-dioxygenase or catechol 2,3dioxygenase, which indicates that the pathway does not proceed through a catechol intermediate. Cells grown on 4FP oxidized 4-FP, hydroquinone, and hydroxyquinol but not 4-fluorocatechol. During 4-FP metabolism, hydroquinone accumulated as a product. Hydroquinone could be converted to hydroxyquinol, which was further transformed into maleylacetic acid and $\beta$-ketoadipic acid. These results
\end{abstract}

M. I. M. Ferreira • D. B. Janssen $(\bowtie)$

Department of Biochemistry,

Groningen Biomolecular Sciences and Biotechnology Institute,

University of Groningen,

NL-9747 AG Groningen, The Netherlands

e-mail: d.b.janssen@rug.nl

\section{J. R. Marchesi}

Department of Microbiology/Alimentary Pharmabiotic Centre, University College Cork,

College Road,

Cork, Ireland indicate that the biodegradation of 4-FP starts with a 4-FP monooxygenase reaction that yields benzoquinone, which is reduced to hydroquinone and further metabolized via the $\beta$-ketoadipic acid pathway.

Keywords Biodegradation · 4-Fluorophenol . Hydroquinone $\cdot$ Monooxygenase $\cdot$ Fluoride

\section{Introduction}

During the past decades, widespread application of fluoroaromatic compounds as agrochemicals and pharmaceuticals has lead to an increased occurrence of environmental contaminants containing fluorine (Key et al. 1997). Fluorinated compounds are rare in nature (Harper and O'Hagan 1999). The stability of the carbon-fluorine bond (116 kcal/mol in $\mathrm{CH}_{3} \mathrm{~F}$, compared to $81 \mathrm{kcal} / \mathrm{mol}$ for the carbon-chlorine bond in $\mathrm{CH}_{3} \mathrm{Cl}$ ) makes most fluorinecontaining compounds much more resistant to biodegradation than their unsubstituted analogs (Key et al. 1997). Furthermore, the van der Waals radius of fluorine is small (1.47 $\AA$, in between that of a hydrogen and an oxygen). Yet, the electronegativity of fluorine causes strong polarization of C-F bonds, and fluorine substituents may be involved in biological interactions (Howard et al. 1996).

Regardless of the recalcitrance of most fluoroaromatics to biodegradation, several bacterial cultures have been described that aerobically degrade fluorobenzoic acids (Oltmanns et al. 1989; Engesser et al. 1980; Harper and Blakley 1971; Schlomann et al. 1990). Research on bacterial fluorophenol degradation has been limited to studies with whole cells, cell extracts, or purified enzymes from Rhodococcus species that were obtained by enrichment with other aromatic compounds as a growth substrate 
(Boersma et al. 1998, 2001; Bondar et al. 1998, 1999; Finkelstein et al. 2000). The fluorobenzene-degrading organism Rhizobiales F11 could grow on 4-fluorophenol (4-FP), but information on the pathway of 4-FP metabolism is lacking.

Cometabolic degradation of difluorophenols and trifluorophenols by several Rhodococcus species is initiated by a phenol hydroxylase that catalyzes ortho-hydroxylation, resulting in the formation of the respective fluorocatechol, which is then cleaved by an intradiol dioxygenase to produce fluoromuconate (Bondar et al. 1998). Conversion of 4-FP by whole cells of the phenol-degrading organism Rhodococcus opacus $1 \mathrm{cp}$ resulted in the formation of 4fluorocatechol, 1,2,3-trihydroxy-5-fluorobenzene, and fluoromuconates (Finkelstein et al. 2000). Yeasts and fungi that are able to cometabolically transform fluorinated phenols have also been described. Whole cells of Exophiala jeanselmei transformed 4-FP into 4-fluorocatechol and 3fluoromuconate (Boersma et al. 1998). Penicillium frequentans metabolized monofluorophenols in the presence of glucose or phenol. The metabolism of meta-or parafluorophenols yielded the corresponding catechol and 4-carboxymethylenebut-2-en-4-olide (Hofrichter and Schreibner 1993; Hofrichter et al. 1994). None of these organisms could utilize fluorophenols as a growth substrate.

To our knowledge, studies on the metabolism of fluorophenols by a bacterial culture that is capable of using such as compound as a sole source of carbon and energy have not been reported. In the present paper, we describe the isolation and characterization of a bacterial strain growing on 4-FP as the sole source of carbon and energy. Based on the identification of several intermediates, a metabolic route for the degradation of 4-FP by this strain is proposed.

\section{Materials and methods}

Media and growth conditions NB medium contained $8 \mathrm{~g}$ of Nutrient Broth (Difco) per liter. Mineral salts medium (MM) contained per liter $5.3 \mathrm{~g} \mathrm{Na}_{2} \mathrm{HPO}_{4} 12 \mathrm{H}_{2} \mathrm{O}, 1.4 \mathrm{~g} \mathrm{KH}_{2} \mathrm{PO}_{4}$, $0.2 \mathrm{~g} \mathrm{MgSO}_{4} 7 \mathrm{H}_{2} \mathrm{O}, 0.5 \mathrm{~g}\left(\mathrm{NH}_{4}\right)_{2} \mathrm{SO}_{4}, 5 \mathrm{ml}$ trace metals solution (Janssen et al. 1985), and $10 \mathrm{mg}$ of yeast extract (Difco Laboratories). When required, the solid medium was obtained by adding $15 \mathrm{~g} / 1$ of Difco agar. Strain IF1 was grown at $30^{\circ} \mathrm{C}$ on a rotary shaker $(180 \mathrm{rpm})$. Cultures were grown in $100-\mathrm{ml}$ flasks filled to $25 \%$ of their volume and were closed with Teflon-lined screw caps. E. coli cells were grown in Luria-Bertani medium (LB) at $37^{\circ} \mathrm{C}$ on a rotary shaker.

Enrichment and isolation of 4-FP-degrading cultures A variety of soil samples, collected from different sites in The Netherlands that are contaminated with halogenated aliphatic compounds (such as monochlorobenzene, hexachlor- obenzene, and trichloropropane), were used as the initial inoculum for the 4-FP enrichments. The soil samples were used to inoculate flasks containing $30 \mathrm{ml}$ of sterile minimal salts medium and $1 \mathrm{mM}$ of 4-FP, supplied in the liquid phase as the sole carbon and energy source. The cultures were incubated at room temperature on a rotary shaker (150 rpm), and $40 \%$ of the suspension was transferred to a new flask containing fresh medium every 15 days. During this time, growth (optical density at $600 \mathrm{~nm}$ ) and liberation of fluoride were monitored. Samples of the enrichment culture were periodically spread onto minimal salts agar plates containing $1 \mathrm{mM} 4-\mathrm{FP}$ and onto NB plates as soon as growth on 4-FP was established. Pure cultures were obtained by repetitive streaking onto solid MM containing 4-FP and tested separately for growth on $1 \mathrm{mM}$ 4-FP liquid medium. Growth and fluoride release were again monitored to verify 4-FP degradation. Strains capable of 4-FP degradation as a sole source of carbon and energy were used for further experiments. Strain IF1 was deposited at Centraalbureau voor Schimmelcultures, Utrecht, The Netherlands, under accession number NCCB 100218.

Sequencing of the $16 S$ rRNA gene For cloning of the $16 \mathrm{~S}$ ribosomal ribonucleic acid (rRNA) gene, a single colony of strain IF1 was directly used for polymerase chain reaction (PCR) amplification. The primers 63f (5'-CAGGCCTAAC ACATGCAAGTC-3') and 1387r (5'-GGGCGGWGTGTA CAAGGC-3'; Marchesi et al. 1998) were used for PCR amplification. The PCR reaction mixture $(50 \mu \mathrm{l})$ contained Taq PCR buffer, $2.5 \mathrm{mM} \mathrm{MgCl} 2,20$ pmol of each appropriate primer, $200 \mathrm{mM}$ of each deoxyribonucleotide triphosphate, $1 \mathrm{U} \mathrm{Taq}$ DNA polymerase, and biomass of strain IF1. The PCR conditions were $94^{\circ} \mathrm{C}$ for $10 \mathrm{~min}$ followed by $1 \mathrm{~min}$ at $95^{\circ} \mathrm{C}, 1 \mathrm{~min}$ at $55^{\circ} \mathrm{C}, 1.5 \mathrm{~min}$ at $72^{\circ} \mathrm{C}$, and $5 \mathrm{~min}$ at $72^{\circ} \mathrm{C}$. The resulting fragments were cloned into the pCR4-TOPO vector (Invitrogen, Carlsbad, CA) and transformed into $E$. coli TOP10 cells. The transformed cells were plated on LB plates containing $0.5 \mathrm{mg} / \mathrm{ml}$ of ampicillin, and the positive colonies were used for plasmid isolation and sequencing.

Phylogenetic analysis Alignments of the 16S rRNA gene were made using sequences downloaded from the Ribosomal database project II (RDP II; Cole et al. 2005), after searching for nearest neighbors using the sequence match tool. Further searches were conducted using BLAST and FASTA of the European Molecular Biology Laboratory (EMBL) database for 16S rRNA gene sequences that are closely related to the 16S rRNA gene of strain IF1 but not available from the RDP II. Alignments were subsequently made using the profile alignment option in ClustalX (Thompson et al. 1997), refined using BioEdit ver 7.0.5.2 (Hall 1999), and subsequently parsed through Gblock 
(Castresana 2000) to remove ambiguously aligned sections and increase the robustness of the data. Phylogenetic trees were determined using the neighbor-joining (NJ) method. Evolutionary distances for the global tree were calculated using the Kimura-2-parameter model with a transition/ transversion ratio of 2 (Fig. 1). Further trees were constructed in Phylip version 3.6a3 (J. Felsenstein), using maximum parsimony and maximum likelihood methods. All NJ trees were tested statistically by means of bootstrap analysis.

Preparation of cell extracts Cells were grown in MM with $4 \mathrm{mM}$ 4-FP, harvested by centrifugation at $5,000 \times g$ for $15 \mathrm{~min}$, washed with ice-cold TD buffer $(0.1 \mathrm{M}$ Tris- $\mathrm{HCl}$, $\mathrm{pH} 7.5$, and $0.1 \mathrm{M} \mathrm{1,4-dithiothreitol),} \mathrm{and} \mathrm{stored} \mathrm{at}-20^{\circ} \mathrm{C}$ until further use. The frozen cells were thawed, resuspended in TD buffer, and incubated with lysozyme $(50 \mathrm{mg} / \mathrm{ml})$ for $1 \mathrm{~h}$ at $30^{\circ} \mathrm{C}$. A French press was used to disrupt the cells, and the crude extracts were centrifuged at $10,000 \times g$ for $15 \mathrm{~min}$ to separate the soluble from the particulate fraction. The supernatant was used for further experiments. Protein concentrations were determined with the Biorad protein assay kit.
Enzyme assays Catechol 1,2-dioxygenase and catechol 2,3dioxygenase activities were measured spectrophotometrically at 260 and $375 \mathrm{~nm}$, respectively. The reaction mixtures contained $0.1 \mathrm{mM}$ catechol, TD buffer, and cellfree extract $(0.1 \mathrm{mg}$ of protein) in a final volume of $1 \mathrm{ml}$. 4Fluorocatechol 1,2-dioxygenase was measured as catechol 1,2-dioxygenase but with 4-fluorocatechol instead of catechol as the substrate.

The 4-FP monooxygenase activity was measured spectrophotometrically by following the consumption of $\mathrm{NADH}$ at $340 \mathrm{~nm}$ in a reaction mixture containing cellfree extract $(0.1 \mathrm{mg}$ protein), $0.1 \mathrm{mM} 4-\mathrm{FP}, 0.1 \mathrm{mM}$ $\mathrm{NADH}$, and buffer in a total volume of $1 \mathrm{ml}$. The observed rates were corrected for substrate-independent NADH oxidation.

Hydroxymuconic semialdehyde dehydrogenase was measured at $375 \mathrm{~nm}$. Reaction mixtures contained (in a final volume of $1 \mathrm{ml}$ ) about $0.05 \mathrm{mM}$ freshly prepared hydroxymuconic semialdehyde, TD buffer, $0.1 \mathrm{mM} \mathrm{NAD,}$ and cell-free extract $(0.1 \mathrm{mg}$ of protein). Hydroxymuconic semialdehyde was obtained by incubation of catechol with the cell-free extract of Pseudomonas putida mt-2 as described previously (Mars et al. 1998).

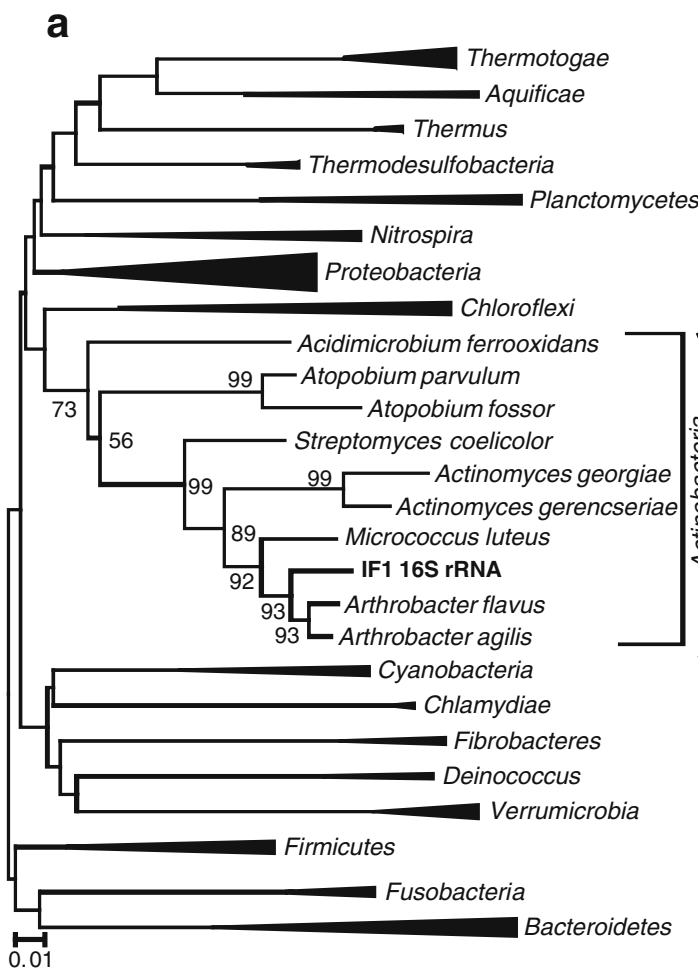

Fig. 1 Phylogenetic tree of the 16S rRNA gene sequence of strain IF1. The scale bar represents 0.1 fixed mutation per site. Bootstrap values were derived from 1,000 analyses. The DNA sequences were aligned using ClustalX, and the tree was constructed by the neighborjoining program from a similarity matrix of pairwise comparisons b

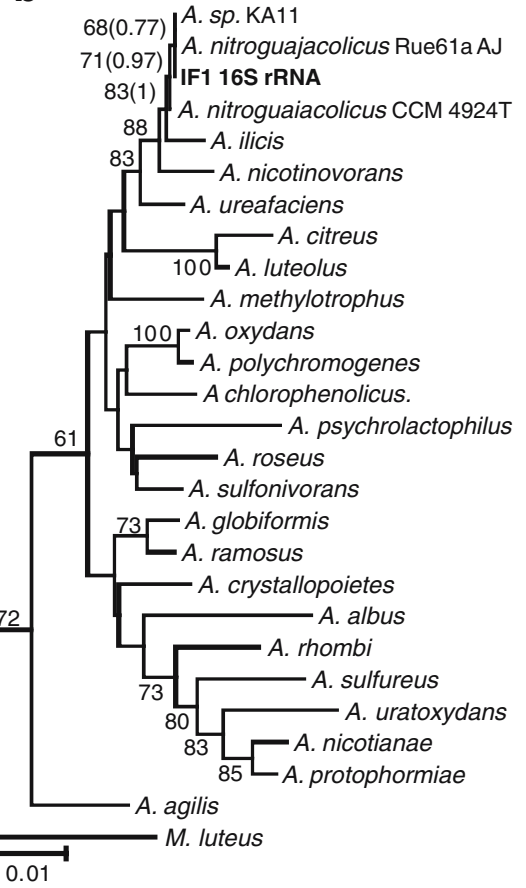

made by using the Kimura-2-parameter algorithm. Tree a shows the global position of the strain IF1 while tree $\mathbf{b}$ shows the Bayesian tree and the more precise relationship of strain IF1 to other members of the genus Arthrobacter. The values in parenthesis in this tree are the posterior probabilities for the nodes that show where IF1 resides 
Hydroquinone dioxygenase was assayed spectrophotometrically by monitoring the change in absorbance between 230 and $330 \mathrm{~nm}$ in a reaction mixture of $1 \mathrm{ml}$ final volume containing $0.1 \mathrm{mM}$ hydroquinone, TD buffer, and cell-free extract ( $0.1 \mathrm{mg}$ of protein). Hydroquinone hydroxylase and hydroxyquinol dioxygenase were assayed by using a fiber optic oxygen sensor. Reaction mixtures contained $1 \mathrm{mM}$ of substrate, $\mathrm{MM}$, and cell suspension $(0.5 \mathrm{mg} / \mathrm{ml}$ protein) in a final volume of $1.25 \mathrm{ml}$.

Oxygen uptake measurements Strain IF1 was grown with glucose or 4-FP as the sole carbon source and harvested by centrifugation at $6,000 \times \mathrm{g}$ for $15 \mathrm{~min}$ at $4^{\circ} \mathrm{C}$. Cells were resuspended in $\mathrm{MM}$, and $\mathrm{O}_{2}$ consumption was measured with a fiber optic oxygen sensor (MOPS-1, ProSense BV, Hannover, Germany). All reactions were performed in a stirred vessel at room temperature. The reaction mixtures contained $1 \mathrm{mM}$ of substrate (4-FP, hydroquinone, 4fluorocatechol, hydroxyquinol, or catechol), MM, and cell suspension $(0.5 \mathrm{mg} / \mathrm{ml}$ protein $)$ in a final volume of $1.25 \mathrm{ml}$.

Analytical methods For capillary gas chromatography (GC), $4 \mathrm{ml}$ samples were extracted with $1 \mathrm{ml}$ of diethyl ether. A model 6890 gas chromatograph (Hewlett-Packard) equipped with a flame ionization detector and a HP-5 column (Agilent 19091J-413, $30 \mathrm{~m} \times 0.25 \mathrm{~mm} \times 0.25 \mu \mathrm{m}$ ) were used for the analysis. GC-mass spectrometry (MS) analysis was carried out with a model 5973 mass selective detector (Hewlett-Packard) coupled to a HP 6890 series injector and a HP1 column (Agilent 19091Z-433; $30 \mathrm{~m} \times$ $0.25 \mathrm{~mm} \times 0.25 \mu \mathrm{m})$. High-performance liquid chromatography (HPLC) was carried out using a Chrompack C18 column $(10 \mathrm{~cm} \times 5 \mathrm{~mm})$ connected to a Jasco UV-1575 detector, which monitored absorbance at 214 and $254 \mathrm{~nm}$, and operated with Jasco PU-980 pumps and a Jasco AS-1555 sampler. The mobile phase was water/acetonitrile (70:30), $5 \mathrm{mM}$ potassium phosphate $(\mathrm{pH}=3)$, and $340 \mathrm{mg} / \mathrm{l}$ sodium dodecyl sulfate, and the flow rate was $1 \mathrm{ml} / \mathrm{min}$.

Liquid chromatography (LC)-MS was carried out with a ZMD Micromass spectrometer, equipped with a XTerra MS, Symmetry Shield C 8 column $(4.6 \times 150 \mathrm{~mm})$, a Waters 996 photodiode array detector, and a Waters 2690 separations module. Samples of $20 \mu \mathrm{l}$ were analyzed, and compounds were isocratically eluted at a flow rate of $1 \mathrm{ml} / \mathrm{min}$ with a solution of water/acetonitrile (80:20) and $10 \mathrm{mM}$ formic acid.

Concentrations of free fluoride in the culture supernatants were measured with a fluoride electrode (model 9609, Thermo Russell, Scotland). Fresh sodium fluoride standards were prepared for calibration curves.

Chemicals 4-FP ( $>98 \%$ ) was obtained from Sigma-Aldrich (Steinheim, Germany). All chemicals were of the highest purity grade available (Sigma-Aldrich; Acros Organics, Geel, Belgium). The compound 4-fluorocatechol was kindly provided by Dr. Erik de Vries. Purity of 4-FP, 4fluorocatechol, and hydroquinone was checked by HPLC.

Nucleotide sequence accession numbers The 16S rRNA sequence of strain IF1 was deposited at GenBank with the accession no. DQ425093.

\section{Results}

Isolation of a 4-FP-degrading bacterium To obtain a bacterial culture that is able to use 4-FP as carbon and energy source for growth, enrichments were performed and followed over time. Two months of selective enrichment by repeated transfer of samples from a culture that displayed growth on 4-FP to fresh 4-FP containing media resulted in a microbial consortium that was capable of growth on 4-FP as a sole source of carbon and energy. Samples of the consortium were repeatedly plated onto NB agar plates and MM agar plates containing 4-FP. This procedure resulted in the isolation of three pure strains named IF1, IF2, and IF3. The strains were restreaked on MM supplemented with 4FP and inoculated in liquid cultures with $1 \mathrm{mM}$ 4-FP. Fluoride liberation was observed for all three strains but not in control incubations to which no bacterial inoculum was added. All the three strains showed growth, as monitored at $600 \mathrm{~nm}$, and thus were able to use 4-FP as a sole carbon and energy source. After 5 days of incubation in liquid culture supplied with $1 \mathrm{mM}$ 4-FP, strain IF1 reached $100 \%$ fluoride release and an optical density (OD) of 0.119 at $600 \mathrm{~nm}$. Strain IF2 released $76 \%$ of the fluorine and reached an $\mathrm{OD}_{600}$ of 0.09 , while strain IF3 reached an OD of 0.076 and released $54 \%$ of the theoretical amount of fluoride ions. When a mixed culture of the three strains in liquid media was used, an $\mathrm{OD}_{600}$ of 0.217 and $100 \%$ fluorine release were measured after 4 days. Apparently, the mixed culture contained, even after prolonged adaptation, organisms with varying efficiencies of 4-FP utilization. Because strain IF1 showed the highest degradation rates combined with stoichiometric release of fluoride, this organism was chosen for further studies.

Microbiological characterization Strain IF1 is a Grampositive motile bacterium with a rhodococcus lifecycle. The optimal temperature for growth is $30^{\circ} \mathrm{C}$. The $16 \mathrm{~S}$ rRNA gene sequence was determined. Initial searches against the RDP II and EMBL rRNA databases resulted in very close associations with members of the genus Arthrobacter, the closest of which were the quinaldine-degrading strain Arthrobacter sp. KA1-1 (Overhage et al. 2005) and the 4- 
nitroguaiacol-degrading actinobacterium Arthrobacter nitroguajacolicus sp. nov (Kotouckova et al. 2004). The 16S rRNA gene sequences of these organisms were greater than $99 \%$ identical to IF1's. The phylogenetic analysis places the isolates in the phylum Actinobacteria and the genus Arthrobacter (Fig. 1). The subtree that were obtained shows the detailed relationship of isolate IF1 to other members of the genus Arthrobacter. The topologies of all the trees that were obtained during statistical analysis were in agreement and clearly placed this isolate in the genus Arthrobacter (data not shown). Furthermore, the change in form during the growth cycle between rod and coccus is typical of the lifecycle of the Arthrobacter genus.

Catabolic activities of Arthrobacter sp. strain IF1 To study the degradation potential of strain IF1, a range of organic compounds were tested as growth substrates. Cells were inoculated into $\mathrm{MM}$, and different organic substrates were added at a concentration of $1 \mathrm{mM}$. After 72-h incubation growth, substrate disappearance and halide release were measured.

Growth and substrate removal were found when catechol, hydroquinone, hydroxyquinol, benzoate, phenol, 4-fluorocinnamic acid, and 4-nitrophenol were used as substrates. The organism did not grow on 2-fluorophenol, 3fluorophenol, 4-chlorophenol, 4-bromophenol, 4-iodophenol, fluoroacetate, trifluoroacetate, fluoroacetamide, trifluoroethanol, or on 2-bromoethanol. The fact that strain IF1 is capable of growth on catechol, hydroquinone, and hydroxyquinol but not on 4-fluorocatechol indicates that 4-fluorocatechol is not the most likely intermediate in the 4-FP pathway, although toxic effects could also play a role.

To test the range of 4-FP concentrations tolerated by strain IF1, experiments were conducted in sealed flasks with 4-FP at concentrations of 1 to $7 \mathrm{mM}$ as a sole carbon and energy source. Control assays without 4-FP showed no growth or release of fluoride, and sterile controls showed no abiotic loss of 4-FP. Between 1 and $4 \mathrm{mM} \mathrm{4-FP,} \mathrm{the}$ substrate was completely consumed, stoichiometric release of fluoride was observed, and biomass increased linearly with the amount of 4-FP added (Fig. 2a). This indicates that the degradation of 4-FP by strain IF1 does not give large amounts of fluorinated dead-end products. Concentrations of 4-FP above $4 \mathrm{mM}$ caused a toxic effect on the growth of IF1 (Fig. 2b). The use of $5 \mathrm{mM}$ 4-FP promoted growth, but a longer lag time was observed. At $7 \mathrm{mM} 4-\mathrm{FP}$, no growth occurred even after 15 days of incubation.

Growth on 4-FP and formation of metabolites A batch culture of strain IF1 supplied with $1 \mathrm{mM} 4-\mathrm{FP}$ as the only source of carbon and energy was monitored in time. Growth was accompanied by an increase in biomass, decrease in 4-FP, and formation of fluoride (Fig. 3). After $120 \mathrm{~h}$, there was complete conversion of $1 \mathrm{mM}$ 4-FP, and $1 \mathrm{mM}$ fluoride was formed, indicating that there was no transient accumulation of fluorinated intermediates over the whole growth period. When cells grown on 4-FP were incubated in the presence of the iron chelator $2,2^{\prime}$-dipyridyl, no 4-FP degradation occurred, and no fluoride was released in the medium. This indicates that initial or further enzymes involved in 4-FP metabolism require ferrous ions for activity.

To isolate intermediates of the degradation of 4-FP, samples from a batch culture containing $4 \mathrm{mM}$ 4-FP were taken at appropriate intervals and analyzed by GC, HPLC, and LC-MS. Metabolites that were detected were numbered in order of time of appearance in the culture. GC analysis indicated that at least four metabolites were formed and degraded over time (Table 1). Metabolite I, the earliest

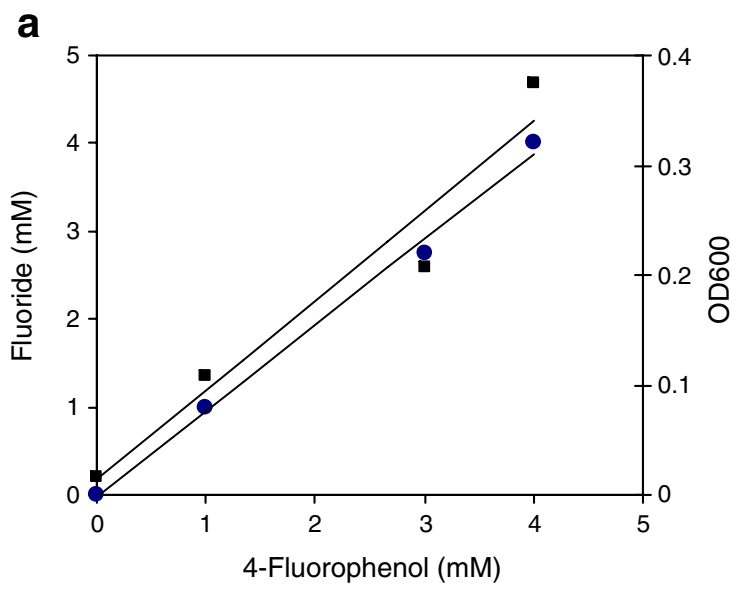

Fig. 2 Fluoride release and biomass formation by strain IF1 with different concentrations of 4-FP. a Stoichiometric fluoride release. Symbols: squares, optical density at $600 \mathrm{~nm}$; circles, fluoride b

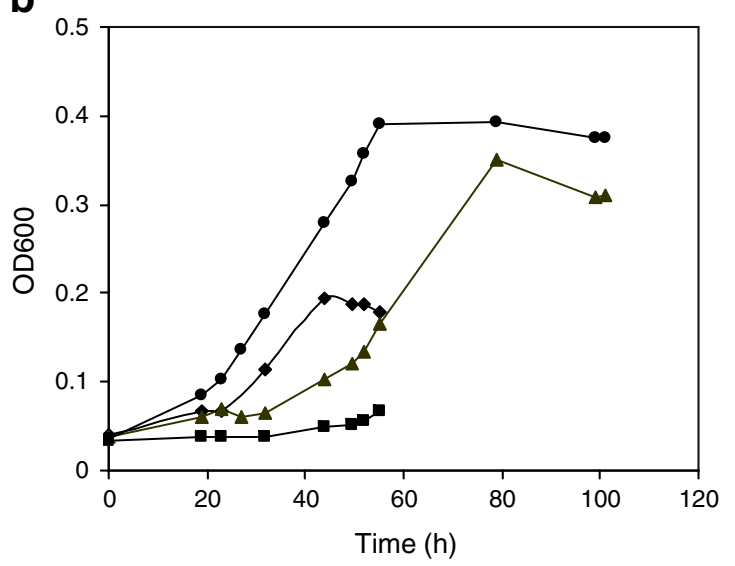

concentration. b Growth in the presence of different levels of 4-FP. The initial concentrations used were: triangles, $1 \mathrm{mM} \mathrm{4-FP;} \mathrm{circles,}$ $4 \mathrm{mM}$ 4-FP; diamonds, $5 \mathrm{mM}$ 4-FP; squares, $7 \mathrm{mM}$ 4-FP 


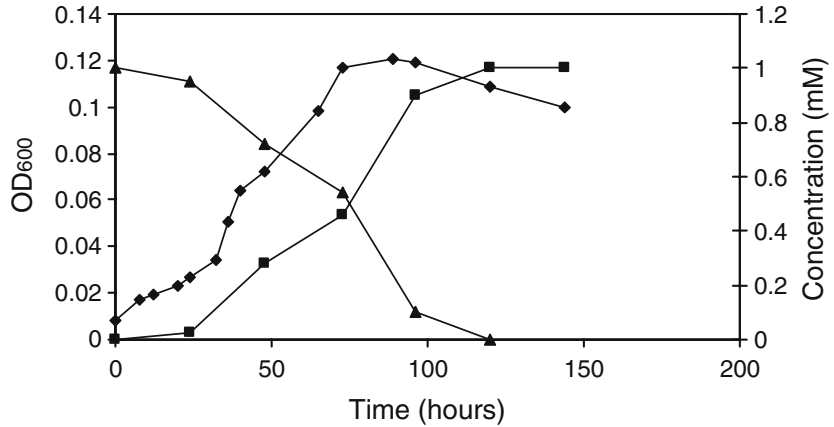

Fig. 3 Biodegradation of 4-FP and fluoride liberation in a batch culture of strain IF1. The carbon source used is $1 \mathrm{mM}$ 4-FP. Symbols: triangles, 4-FP concentration; diamonds, optical density; squares, fluoride concentration

product that was observed, had the same retention time as an authentic hydroquinone standard and metabolite II had the same retention time as a standard of hydroxyquinol. GC-MS analysis showed that the mass spectrum of metabolite I was indeed similar to that of the hydroquinone standard, with a molecular ion peak at 110 and at $55 \mathrm{~m} / \mathrm{z}$. Metabolite II gave a molecular ion peak at 126 and $63 \mathrm{~m} / \mathrm{z}$, which is typical for hydroxyquinol, and the spectrum coincided with that of a standard. Metabolites V and VI were detected by GC but did not ionize in GC-MS under the conditions tested and were not identified.

When the supernatant of IF 1 cells growing on $4 \mathrm{mM} 4-\mathrm{FP}$ were subjected to HPLC analysis, four peaks were detected

Table 1 Retention times in GC and HPLC analyses of metabolic intermediates formed by cells of strain IF1 growing on 4-FP and of some authentic standards

\begin{tabular}{llll}
\hline Compound & GC & HPLC & $m / z$ of observed \\
& retention & retention & fragment ions \\
time $(\mathrm{min})$ & time $(\mathrm{min})^{\mathrm{a}}$ & detected by GC-MS \\
\hline
\end{tabular}

\begin{tabular}{llll}
\hline Metabolites & & & \\
I & 20.7 & 1.3 & $110,81,54$ \\
II & 24.3 & 1.1 & $126,80,52$ \\
III & $-^{\mathrm{c}}$ & 0.75 & - \\
IV & - & 2.6 & - \\
V & 16.5 & - & - \\
VI & 19.4 & - & - \\
VII & - & $3.1^{\mathrm{b}}$ & $159,80^{\mathrm{d}}$ \\
Authentic standards & & & \\
4-FP & 15.7 & 3 & $112,83,57$ \\
4-Fluorocatechol & 14.4 & 2 & $128,82,51$ \\
Hydroquinone & 20.7 & 1.3 & $110,81,54$ \\
Hydroxyquinol & 24.3 & 1.1 & $126,80,52$ \\
Catechol & 19.1 & - & -
\end{tabular}

${ }^{\text {a }}$ Elution followed at $254 \mathrm{~nm}$

${ }^{\mathrm{b}}$ Analyzed after separation on a Symmetry Shield C8 column $(4.6 \mathrm{~mm} \times 150 \mathrm{~mm})$ as described in "Materials and methods" for LCMS analysis

c - Not determined

${ }^{\mathrm{d}}$ LC-MS analysis

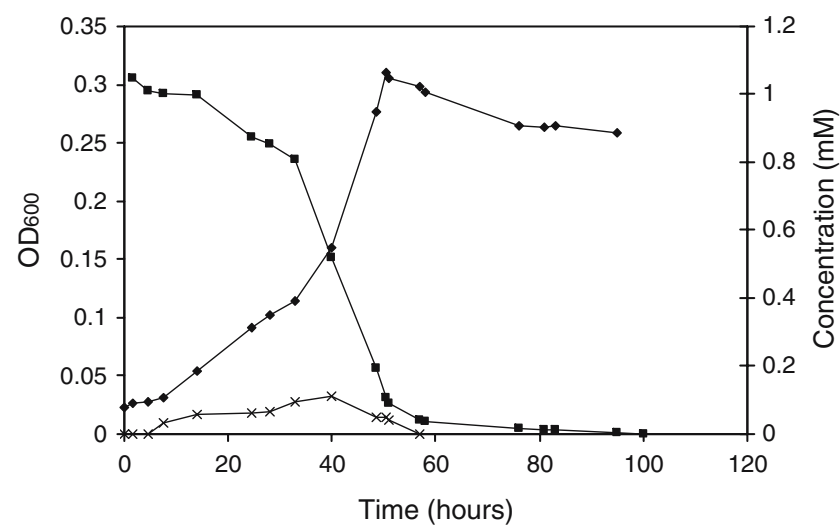

Fig. 4 Accumulation of hydroquinone during growth of strain IF1 on $4 \mathrm{mM}$ 4-FP. The optical density (diamonds), 4-FP concentration (squares), and hydroquinone concentration (x marks) are indicated. Hydroquinone was identified by GC-MS and quantified by GC-FID

(Table 1). Metabolite I had the same retention time as the hydroquinone standard, and metabolite II coeluted with an authentic standard of hydroxyquinol. Hydroquinone was detected in culture supernatants by HPLC between 7.5 and $51 \mathrm{~h}$ (Fig. 4). LC-MS analysis of the extracted samples of the supernatant revealed the presence of a compound (VII) of which the negative ion spectrum shows a molecular ion peak at $159 \mathrm{~m} / \mathrm{z}$ and a peak at $80 \mathrm{~m} / \mathrm{z}$, which are expected for the negative ionization of 3-oxoadipate.

The above results suggest that 4-FP is initially converted to hydroquinone. The most likely enzyme involved in such a conversion is a 4-FP monooxygenase.

Enzyme activities To test inducibility of enzymes involved in 4-FP degradation, cells of Arthrobacter sp. strain IF1 were grown on glucose or 4-FP, washed, and tested for oxygen consumption in the presence of different substrates. Washed suspensions of cells grown on 4-FP rapidly oxidized 4-FP, hydroquinone, and 1,2,4-benzenetriol (hydroxyquinol) without a lag. Catechol and 4-fluorocatechol did not stimulate

Table 2 Substrates oxidized by 4-FP and glucose grown cells of Arthrobacter sp. strain IF $1^{\text {a }}$

\begin{tabular}{lll}
\hline Assay substrate & \multicolumn{2}{l}{$\begin{array}{l}\mathrm{O}_{2} \text { uptake }(\mu \mathrm{mol} / \mathrm{min} / \mathrm{mg} \text { of protein) by whole } \\
\text { cells after growth on }\end{array}$} \\
\cline { 2 - 3 } & Fluorophenol & Glucose \\
\hline 4-Fluorophenol & 0.356 & $<0.001$ \\
Hydroquinone & 0.313 & $<0.001$ \\
Hydroxyquinol & 0.195 & 0.156 \\
4-Fluorocatechol & $<0.001$ & $<0.001$ \\
Catechol & $<0.001$ & $<0.001$
\end{tabular}

a Oxygen consumption was measured with an oxygen sensor as described in Materials and Methods. All substrate were used at a concentration of $1 \mathrm{mM}$ 
Table 3 Specific activities of enzymes in crude extracts of strain IF1 pregrown in 4-FP or glucose

\begin{tabular}{|c|c|c|c|}
\hline \multirow[t]{2}{*}{ Assay substrate } & \multirow[t]{2}{*}{ Enzyme tested } & \multicolumn{2}{|c|}{$\begin{array}{l}\text { Specific activity } \\
\text { (U/mg of protein) after } \\
\text { growth on }\end{array}$} \\
\hline & & 4-Fluorophenol & Glucose \\
\hline \multirow[t]{2}{*}{ Catechol } & 1,2-Dioxygenase & $<0.01$ & $<0.01$ \\
\hline & 2,3-Dioxygenase & $<0.01$ & $<0.01$ \\
\hline 4-Fluorocatechol & Dioxygenase & $<0.01$ & $<0.01$ \\
\hline 4-Fluorophenol & Monooxygenase & 0.12 & $<0.01$ \\
\hline \multirow[t]{2}{*}{ Hydroquinone } & Dioxygenase & $<0.01$ & $<0.01$ \\
\hline & Monooxygenase & 0.313 & $<0.01$ \\
\hline $\begin{array}{l}\text { Hydroxymuconic } \\
\text { semialdehyde }\end{array}$ & Dehydrogenase & $<0.01$ & $<0.01$ \\
\hline Hydroxyquinol & Dioxygenase & 0.195 & 0.156 \\
\hline
\end{tabular}

oxygen uptake (Table 2). This result indicates that 4fluorocatechol and catechol are not likely intermediates and that hydroquinone and hydroxyquinol are. Glucose-grown cells did not oxidize any of the aromatic substrates tested with the exception of hydroxyquinol. This observation implies that hydroxyquinol may be converted by a constitutive oxygenase, whereas most other enzymes seem inducible. Cells grown with hydroxyquinol showed complete conversion of benzenetriol in the presence or absence of 2,2'dipyridyl, indicating that the putative hydroxyquinol oxygenase does not require ferrous ions to be active and that oxidation beyond this compound is not inhibited by the chelator. The formation of hydroquinone, which can be readily oxidized by 4-FP-grown cells, is in agreement with the involvement in 4-FP degradation of a 4-FP monooxygenase that is induced by 4-FP.

To study in more detail the degradation pathway of 4-FP by strain IF1, cell-free extracts of IF1 grown on 4-FP were investigated for the presence of several enzyme activities (Table 3). When catechol 1,2- and 2,3-dioxygenases were tested for, no activity was found. Furthermore, no activity was detectable for 4-fluorocatechol dioxygenase. Consequently, the pathway does not proceed through catechol or a substituted catechol. When cell extracts were assayed for 4-FP monooxygenase, activity could be found in the presence of NADH but not in the presence of NADPH as the reducing cosubstrate. This observation indicates that the cells contain an NADH-dependent 4-FP monooxygenase activity. HPLC assays of incubations of cell extracts with 4FP showed that substrate conversion was complete. The formation of the putative 4-FP monooxygenase was induced by 4-FP because no activity was found in extracts of cells grown in the presence of glucose.

When hydroquinone was used as an assay substrate, its typical spectrophotometric peak at $288 \mathrm{~nm}$ was not replaced by a peak absorbing at 290 to $320 \mathrm{~nm}$, which would have pointed to formation of hydroxymuconic semialdehyde. Thus, no hydroquinone dioxygenase was induced, or its product was rapidly further converted. The latter was ruled out by the observation that added hydroxymuconic semialdehyde was not converted by cell extracts of strain IF1, indicating that no hydroxymuconic semialdehyde dehydrogenase was induced during growth in the presence of 4-FP. These results make it unlikely that hydroxymuconic semialdehyde is an intermediate in the 4-FP pathway by strain IF1.

When cell extracts were assayed for hydroxyquinol degradation, complete conversion of the substrate was observed with HPLC. When the reaction was monitored spectrophotometrically, the peak at $287 \mathrm{~nm}$, typical of hydroxyquinol, was substituted by a peak at $245 \mathrm{~nm}$, typical of maleylacetate. This indicates the involvement of a hydroxyquinol oxygenase that converts hydroxyquinol into maleylacetate, which is further converted into 3-oxoadipate.

\section{Discussion}

This study reports the isolation and characterization of Arthrobacter strain IF1, an organism capable of growth with 4-FP as a sole source of carbon and energy. The biodegradation of 4-FP by strain IF1 was analyzed by GC, GC-MS, HPLC, LC-MS, oxygen uptake experiments, and measurements of enzymatic activities. A metabolic pathway is proposed on the basis of the results of this study (steps 1 and 2, ortho-cleavage) and by analogy with other systems
Fig. 5 Proposed pathway for 4fluorophenol degradation by Arthrobacter sp. strain IF1. Hydroquinone and hydroquinole were identified as intermediates by GC-MS

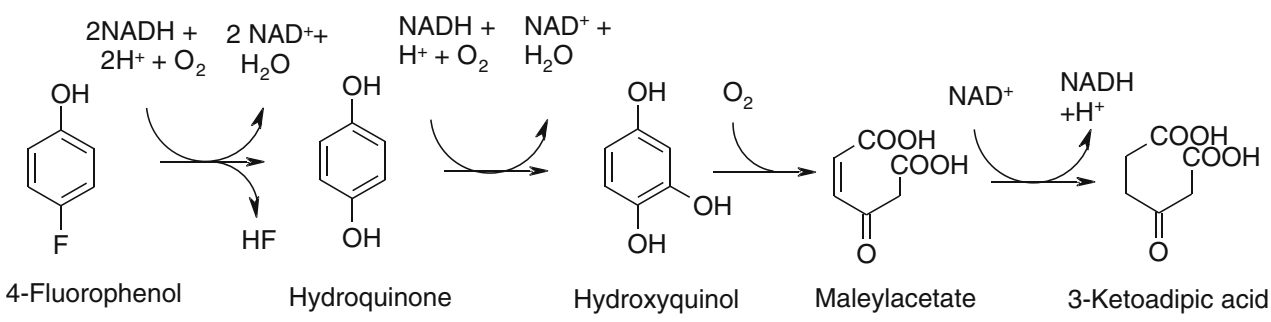


(Fig. 5). We suggest that the degradation of 4-FP in strain IF1 starts with the conversion by a monooxygenase to benzoquinone, which is immediately reduced to hydroquinone. Hydroquinone then undergoes a further hydroxylation to form hydroxyquinol. This benzenetriol is the ring fission substrate, which is transformed by ortho-cleavage and yields maleylacetate, which is further converted to 3oxoadipate.

Up to now, two main metabolic routes for the aerobic degradation of halogenated phenols have been described in the literature. In bacteria that degrade mono- and dichlorophenols, a degradation pathway is usually observed in which the substituted phenol is hydroxylated to the corresponding catechol, which is followed by orthocleavage of the aromatic ring (Haggblom 1992; Hollender et al. 1997; Wieser et al. 1994). On the other hand, biodegradation pathways in which the substituted phenol is converted via hydroquinone to maleylacetate have been found, mainly in organisms that grow on polyhalophenols or 4-nitrophenol (Kiyohara et al. 1992; Xun et al. 1992; Kadiyala and Spain 1998; Nordin et al. 2005; Perry and Zylstra 2007). Most studies have focused on the organisms and pathways that involve degradation via catechols.

A clear indication for the first step in the 4-FP catabolic pathway of strain IF1 was obtained by mass spectroscopic analysis of culture supernatants, which indicated the formation of hydroquinone as an early nonfluorinated intermediate. This result, in combination with the enzyme assays and oxygen uptake experiments, suggests the involvement of an inducible 4-FP monooxygenase that is NADH dependent, although the first expected product of this reaction, i.e., benzoquinone, was not detected. Monooxygenation of an aromatic substrate carrying an electronwithdrawing halogen group or a nitro-substituent can result in simultaneous hydroxylation and dehalogenation or nitrite removal. This has, for example, been described for the conversion of tetrafluoro- $p$-hydroxybenzoate by parahydroxybenzoate hydroxylase (Husain et al. 1980) and the oxidation of 2,4-6-trifluorophenol by a monooxygenase from Ralstonia eutropha JMP134 (Xun and Webster 2004). The quinone that is produced is chemically reduced by $\mathrm{NADH}$ to a hydroxyquinol, leading to a net stoichiometry of two NADH oxidized per halide or nitrite that is released (Fig. 5). As in our case, no transient accumulation of a benzoquinone is usually observed, indicating that benzoquinone reduction is rapid. Other examples of halophenol degradation with formation of hydroquinone derivatives are the degradation of trichlorophenol to 2,6-dichlorohydroquinone by a strain of Pseudomonas pickettii (Kiyohara et al. 1992), the degradation of pentachlorophenol by a Sphingobium sp. through hydroxylation by a flavoprotein monooxygenase (Xun and Orser 1991), and the degradation of 4-chlorophenol by an Arthrobacter sp. (Bae et al. 1996).
Our results further indicate that hydroquinone is not the ring fission substrate because no enzymatic activities for hydroquinone dioxygenase or hydroxymuconic semialdehyde dehydrogenase were found. Instead, upon conversion of hydroquinone by strain IF1, we observed the formation of a transient metabolite that was identified as hydroxyquinol, indicating that a second hydroxylation takes place before ring fission. The production of hydroxyquinol could be due to the action of a separate hydroquinone monooxygenase, or it could be caused by a second hydroxylation step by the 4-FP monooxygenase. Conversion of hydroquinone to hydroxyquinol before ring fission was also suggested for strains Arthrobacter that degrade 4-nitrophenol (Perry and Zylstra 2007) and 4-chlorophenol (Nordin et al. 2005). Ring fission of hydroxyquinol would produce maleylacetate, which we did not detect as an intermediate in 4-FP degradation, but a transient metabolite was found with mass properties identical to those of 3oxoadipate, which is expected to be the next intermediate in hydroxyquinol degradation.

Most cometabolic transformations of fluorophenols described in the literature involve the initial action of a phenol hydroxylase that results in the formation of fluorocatechols, which are subsequently transformed into fluoromuconates through a catechol 1,2-dioxygenase. The conversion usually proceeds with lactonization and elimination of fluoride (Boersma et al. 2001; Bondar et al. 1999; Finkelstein et al. 2000; Boersma et al. 1998; Bondar et al. 1998). Our results suggest that Arthrobacter strain IF1, which grows on 4-FP, possesses a new pathway for the degradation of 4-FP that involves immediate defluorination by a monooxygenase. Strain IF1 avoids the accumulation of possible toxic metabolites such as 3- or 4-fluorocatechol by this initial dehalogenation.

Acknowledgments This work was supported in part by the European Community Human Potential Programme under contract HPRTN-CT-2002-00213 [BIOSAP]. We thank Erik de Vries for 4fluorocatechol preparation and Piet Wietzes for technical assistance.

Open Access This article is distributed under the terms of the Creative Commons Attribution Noncommercial License which permits any noncommercial use, distribution, and reproduction in any medium, provided the original author(s) and source are credited.

\section{References}

Bae HS, Lee JM, Lee ST (1996) Biodegradation of 4-chlorophenol via a hydroquinone pathway by Arthrobacter ureafaciens CPR706. FEMS Microbiol Lett 145:125-129

Boersma MG, Dinarieva TY, Middelhoven WJ, van Berkel WJ, Doran J, Vervoort J, Rietjens IM (1998) 19F nuclear magnetic resonance as a tool to investigate microbial degradation of 
fluorophenols to fluorocatechols and fluoromuconates. Appl Environ Microbiol 64:1256-1263

Boersma MG, Solyanikova IP, van Berkel WJ, Vervoort J, Golovleva LA, Rietjens IM (2001) 19F NMR metabolomics for the elucidation of microbial degradation pathways of fluorophenols. $\mathrm{J}$ Ind Microbiol Biotechnol 26:22-34

Bondar VS, Boersma MG, Golovlev EL, Vervoort J, van Berkel WJ, Finkelstein ZI, Solyanikova IP, Golovleva LA, Rietjens IM (1998) ${ }^{19}$ F NMR study on the biodegradation of fluorophenols by various Rhodococcus species. Biodegradation 9:475-486

Bondar VS, Boersma MG, van Berkel WJ, Finkelstein ZI, Golovlev EL, Baskunov BP, Vervoort J, Golovleva LA, Rietjens IM (1999) Preferential oxidative dehalogenation upon conversion of 2halophenols by Rhodococcus opacus 1G. FEMS Microbiol Lett $181: 73-82$

Castresana J (2000) Selection of conserved blocks from multiple alignments for their use in phylogenetic analysis. Mol Biol Evol 17:540-552

Cole JR, Chai B, Farris RJ, Wang Q, Kulam SA, McGarrell DM, Garrity GM, Tiedje JM (2005) The Ribosomal Database Project (RDP-II): sequences and tools for high-throughput rRNA analysis. Nucleic Acids Res 33:D294-D296

Engesser KH, Schmidt E, Knackmuss HJ (1980) Adaptation of Alcaligenes eutrophus B9 and Pseudomonas sp. B13 to 2fluorobenzoate as growth substrate. Appl Environ Microbiol 39:68-73

Finkelstein ZI, Baskunov BP, Boersma MG, Vervoort J, Golovlev EL, van Berkel WJ, Golovleva LA, Rietjens IM (2000) Identification of fluoropyrogallols as new intermediates in biotransformation of monofluorophenols in Rhodococcus opacus 1cp. Appl Environ Microbiol 66:2148-2153

Haggblom MM (1992) Microbial breakdown of halogenated aromatic pesticides and related compounds. FEMS Microbiol Rev 9:29-71

Hall TA (1999) BioEdit: a user-friendly biological sequence alignment editor and analysis program for Windows 95/98/NT. Nucleic Acids Symp Ser 41:95-98

Harper DB, Blakley ER (1971) The metabolism of p-fluorobenzoic acid by a Pseudomonas sp. Can J Microbiol 17:1015-1023

Harper DB, O'Hagan D (1999) Fluorine-containing natural products. J Fluorine Chem 100:127-133

Hofrichter M, Scheibner K (1993) Utilization of aromatic compounds by the Penicillium strain Bi 7/2. J Basic Microbiol 33:227-232

Hofrichter M, Bublitz F, Fritsche W (1994) Unspecific degradation of halogenated phenols by the soil fungus Penicillium frequentans Bi 7/2. J Basic Microbiol 34:163-172

Hollender J, Hopp J, Dott W (1997) Degradation of 4-chlorophenol via the meta cleavage pathway by Comamonas testosteroni JH5. Appl Environ Microbiol 63:4567-4572

Howard JAK, Hoy VJ, O'Hagan D, Smith GT (1996) How good is fluorine as a hydrogen bond acceptor? Tetrahedron 52:1261312622

Husain M, Entsch B, Ballou DP, Massey V, Chapman PJ (1980) Fluoride elimination from substrates in hydroxylation reactions catalyzed by p-hydroxybenzoate hydroxylase. J Biol Chem 255:4189-4197

Janssen DB, Scheper A, Dijkhuizen L, Witholt B (1985) Degradation of halogenated aliphatic compounds by Xanthobacter autotrophicus GJ10. Appl Environ Microbiol 49:673-677
Kadiyala V, Spain JC (1998) A two-component monooxygenase catalyzes both the hydroxylation of p-nitrophenol and the oxidative release of nitrite from 4-nitrocatechol in Bacillus sphaericus JS905. Appl Environ Microbiol 64:2479-2484

Key BD, Howell RD, Criddle CS (1997) Fluorinated organics in the biosphere. Environ Sci Technol 31:2445-2454

Kiyohara H, Hatta T, Ogawa Y, Kakuda T, Yokoyama H, Takizawa N (1992) Isolation of Pseudomonas pickettii strains that degrade 2,4,6-trichlorophenol and their dechlorination of chlorophenols. Appl Environ Microbiol 58:1276-1283

Kotouckova L, Schumann P, Durnova E, Sproer C, Sedlacek I, Neca J, Zdrahal Z, Nemec M (2004) Arthrobacter nitroguajacolicus sp. nov., a novel 4-nitroguaiacol-degrading actinobacterium. Int J Syst Evol Microbiol 54:773-777

Marchesi JR, Sato T, Weightman AJ, Martin TA, Fry JC, Hiom SJ, Dymock D, Wade WG (1998) Design and evaluation of useful bacterium-specific PCR primers that amplify genes coding for bacterial 16S rRNA. Appl Environ Microbiol 64:795-799

Mars AE, Prins GT, Wietzes P, de Koning W, Janssen DB (1998) Effect of trichloroethylene on the competitive behavior of toluene-degrading bacteria. Appl Environ Microbiol 64: $208-215$

Nordin K, Unell M, Jansson JK (2005) Novel 4-chlorophenol degradation gene cluster and degradation route via hydroxyquinol in Arthrobacter chlorophenolicus A6. Appl Environ Microbiol 71:6538-6544

Oltmanns RH, Muller R, Otto MK, Lingens F (1989) Evidence for a new pathway in the bacterial degradation of 4-fluorobenzoate. Appl Environ Microbiol 55:2499-2504

Overhage J, Sielker S, Homburg S, Parschat K, Fetzner S (2005) Identification of large linear plasmids in Arthrobacter spp. encoding the degradation of quinaldine to anthranilate. Microbiology 151:491-500

Perry LL, Zylstra GJ (2007) Cloning of a gene cluster Involved in the catabolism of p-nitrophenol by Arthrobacter sp. strain JS443 and characterization of the p-nitrophenol monooxygenase. J Bacteriol 189:7563-7572

Schlomann M, Fischer P, Schmidt E, Knackmuss HJ (1990) Enzymatic formation, stability, and spontaneous reactions of 4fluoromuconolactone, a metabolite of the bacterial degradation of 4-fluorobenzoate. J Bacteriol 172:5119-5129

Thompson JD, Gibson TJ, Plewniak F, Jeanmougin F, Higgins DG (1997) The CLUSTAL_X windows interface: flexible strategies for multiple sequence alignment aided by quality analysis tools. Nucleic Acids Res 25:4876-4882

Wieser M, Eberspacher J, Vogler B, Lingens F (1994) Metabolism of 4-chlorophenol by Azotobacter sp. GP1: structure of the meta cleavage product of 4-chlorocatechol. FEMS Microbiol Lett 116:73-78

Xun L, Orser CS (1991) Purification and properties of pentachlorophenol hydroxylase, a flavoprotein from Flavobacterium sp. strain ATCC 39723. J Bacteriol 173:4447-4453

Xun L, Webster CM (2004) A monooxygenase catalyzes sequential dechlorinations of 2,4,6-trichlorophenol by oxidative and hydrolytic reactions. J Biol Chem 279:6696-6700

Xun L, Topp E, Orser CS (1992) Confirmation of oxidative dehalogenation of pentachlorophenol by a Flavobacterium pentachlorophenol hydroxylase. J Bacteriol 174:5745-5747 